\title{
Adição de plasma seminal ao sêmen descongelado e taxa de prenhez de ovelhas inseminadas em tempo fixo
}

\author{
[Addition of seminal plasma to frozen-thawed semen and pregnancy rate \\ of fixed time inseminated ewes] \\ O.R. Prado ${ }^{1}$, G.M. Bastos ${ }^{2 *}$, A.L.G. Monteiro ${ }^{3}$, B.B. Saab $^{4}$, S. Gilaverte ${ }^{1}$, C.C. Pierobom ${ }^{5}$, F. Hentz ${ }^{1}$, \\ L.H.S. Martins ${ }^{5}$, C.J.A. Silva ${ }^{1}$, G.S. Dranca ${ }^{5}$, T.S.S. Stivari ${ }^{1}$, G. Cerqueira ${ }^{5}$ \\ ${ }^{1}$ Aluno de pós-graduação/bolsista CAPES - Universidade Federal do Paraná - Curitiba, PR \\ ${ }^{2}$ Unicentro - Guarapuava, PR \\ ${ }^{3}$ Universidade Federal do Paraná - Curitiba, PR \\ ${ }^{4}$ Médico veterinário autônomo - Iretama, PR \\ ${ }^{5}$ Aluno de graduação - Unicentro - Guarapuava, PR
}

\begin{abstract}
RESUMO
Avaliou-se o efeito da adição de plasma seminal ovino ao sêmen descongelado sobre a taxa de prenhez de ovelhas em rebanho comercial. Cento e setenta e quatro ovelhas cruza Texel foram distribuídas em quatro tratamentos: T1) inseminação artificial cervical (IAC) com sêmen descongelado (SD) diluído em solução tampão fosfato salino (PBS); T2) IAC com SD e adição de plasma seminal ovino; T3) grupo-controle I: IAC com sêmen fresco diluído em PBS; T4) grupo-controle II: inseminação artificial por laparoscopia com SD diluído em PBS. Para indução de cio, utilizaram-se esponjas impregnadas com acetato de medroxiprogesterona (MAP) por 12 dias, com aplicação intramuscular de 400 UI de eCG (Novormon ${ }^{\circledR}$ ) e de 37,5 $\mu \mathrm{g}$ de cloprostenol sódico $\left(\right.$ Sincrocio $^{\circledR}$ ), no dia da retirada das esponjas. O aparecimento de cio foi monitorado com rufiões vasectomizados a partir da retirada das esponjas até a inseminação artificial em tempo fixo - 54 a 60 horas. A taxa de prenhez do tratamento com adição de plasma seminal ao sêmen descongelado $(7,0 \%)$ não diferiu $(\mathrm{P}>0,05)$ do tratamento sem adição de plasma $(4,3 \%)$, entretanto foi menor $(\mathrm{P}<0,05)$ se comparada à taxa de prenhez dos grupos-controle I inseminação via cervical superficial com sêmen fresco diluído $(50,0 \%)$ e II inseminação via laparoscopia com sêmen descongelado $(39,4 \%)$. A inseminação artificial por via cervical superficial com adição de plasma seminal ao sêmen descongelado não elevou o percentual de prenhez em valores que justifiquem a indicação desta biotecnologia em rebanhos comerciais de ovinos.
\end{abstract}

Palavras-chave: ovelha, inseminação cervical, laparoscopia

\begin{abstract}
The effect of seminal plasma addition to thawed-frozen ram semen on the pregnancy rate of commercial herd ewes was evaluated. One hundred and seventy-four crossbred Texel sheep were allocated to four treatments: T1) cervical artificial insemination (CAI) using frozen-thawed semen (FTS) diluted in phosphate buffered saline solution (PBS); T2) CAI using FTS diluted in ovine seminal plasma; T3) control group I: CAI using fresh semen diluted in PBS; T4) control group II: laparoscopic insemination using FTS diluted in PBS. Estrus induction was performed with medroxiprogesterone acetate (MAP) impregnated sponges for 12 days, followed by intramuscular injection of 400 IU of eCG (Novormon $\circledR$ ) and $37.5 \mu \mathrm{g}$ of sodium cloprostenol (Sincrocio $囚)$ on the day of sponge removal. Estrus was monitorated with vasectomized rams, beginning at the time of the sponge removal until the fixed time artificial insemination - 54 to 60 hours. The pregnancy rate of FTS diluted in seminal plasma treatment (7.0\%) did not differ $(P>0.05)$ for the treatment without addition of seminal plasma $(4.3 \%)$, however it was lower
\end{abstract}

Recebido em 19 de agosto de 2011

Aceito em 4 de setembro de 2012

*Autor para correspondência (corresponding author)

E-mail: gbastos@unicentro.br 
$(P<0.05)$ when compared to the pregnancy rate of the cervical inseminated control I group with PBS diluted fresh semen (50.0\%) and laparoscopic inseminated control group II with PBS diluted FTS (39.4\%). The cervical artificial insemination with the addition of seminal plasma to frozen-thawed semen did not increase the pregnancy rate at acceptable values to make this biotechnology useful on commercial herds.

Keywords: ewe, cervical insemination, laparoscopy

\section{INTRODUÇÃO}

A inseminação artificial (IA) com sêmen congelado é uma biotecnologia reprodutiva que vem sendo aplicada em rebanhos comerciais e de elite de ovinos.. Esta pode fornecer troca de material genético e aumento da base genética da população de ovinos locais dentro de uma raça, sem a necessidade de transporte dos animais, além de permitir que programas de cruzamento possam ser desenvolvidos, utilizando-se raças de ovelhas que não são adaptadas ao clima dos trópicos (Godfrey et al., 1999). No entanto, as taxas de concepção de ovelhas submetidas a esse procedimento são consideradas baixas. Alguns fatores são descritos como limitadores, entre eles a anatomia do colo do útero (cérvix) da ovelha. Esta estrutura longa é descrita como um órgão fibroso tubular, composto predominantemente por tecido conjuntivo, tortuoso, por apresentar de quatro a sete anéis cervicais e frequentemente desalinhados, dificultando a introdução de pipetas de inseminação pela via cervical além do primeiro anel (Kershaw et al., 2005). A baixa resistência do sêmen de carneiro ao congelamento (Rabassa et al., 2007) é descrita como outro fator limitante da técnica em rebanhos comerciais.

A técnica de laparoscopia tem sido usada para IA intrauterina em rebanhos comerciais de ovinos, entretanto não possui ampla adoção pelas preocupações relacionadas ao bem-estar dos animais, pelas restrições financeiras e pela inacessibilidade aos técnicos não qualificados (Kershaw et al., 2005).

O uso de IA com sêmen fresco ou refrigerado, quando estes são comparados com sêmen congelado, apresenta maiores chances de popularização por requerer técnicas menos sofisticadas de deposição do sêmen no genital feminino (Bicudo et al., 2005).
Outra consideração importante é que o sêmen descongelado via cervical não tem proporcionado resultados satisfatórios de prenhez, em virtude de falhas no transporte ou alterações bioquímicas e moleculares das células submetidas ao processo de congelamento e descongelamento, ou, ainda, pela falta de sobrevivência dos espermatozoides (Evans e Maxwell, 1990). A baixa fertilidade com sêmen descongelado na IA cervical se dá principalmente pelo aumento do número de células capacitadas e acrossoma reagido, resultantes dos processos de diluição (Maxwell e Johnson, 1999), congelação e descongelação (Salamon e Maxwell, 2000).

Com propósito de melhorar a viabilidade do sêmen congelado para posterior utilização em inseminações via cervical, pesquisas têm sugerido a adição de plasma seminal após o descongelamento. O plasma seminal é uma secreção que fornece proteção e transporte aos espermatozoides, sendo proveniente de várias fontes, principalmente das glândulas acessórias do macho. É composto de ácido ascórbico, aminoácidos, peptídeos, proteínas, lipídeos, ácidos graxos e enzimas (Garner e Hafez, 2004). Segundo Kirkwood et al. (2008), quando o plasma seminal é adicionado ao sêmen criopreservado, este interfere na fisiologia do espermatozoide, impedindo a capacitação precoce e aumentando sua vida fértil, além de resultar em maior reservatório de espermatozoides dentro do oviduto, alcançando, assim, o tempo de ovulação e tornando-os capazes de associarem-se às células epiteliais do oviduto para proporcionar maiores taxas de fertilidade. O objetivo deste estudo foi avaliar o efeito da adição de plasma seminal ao sêmen ovino descongelado sobre a taxa de prenhez de ovelhas inseminadas em tempo fixo pela via cervical superficial. 


\section{MATERIAL E MÉTODOS}

O experimento foi realizado em propriedade privada de produção de ovinos, na região de Londrina-PR, entre abril e maio de 2011. Foram utilizadas 174 ovelhas multíparas cruza Texel, com média de escore de condição corporal de 2,5 - escala de 1 a 5 -, mantidas em pastagem de aruana, com acesso a sal mineral e água à vontade. Previamente ao início do experimento, as ovelhas foram submetidas ao exame de ultrassonografia com transdutor linear de $5 \mathrm{MHz}$ para confirmação de ausência de prenhez e distribuídas aleatoriamente em quatro tratamentos: T1) inseminação artificial cervical (IAC) com sêmen descongelado (SD) e adição de solução tampão fosfato salino (PBS) (IAC/SD+PBS; n=49); T2) IAC com SD e adição de plasma seminal ovino (IAC/SD+PS; $\mathrm{n}=43$ ); T3) grupo-controle I: IAC com sêmen fresco diluído (SFD) em PBS (IAC/SFD; $n=44$ ); T4) grupo-controle II: inseminação artificial por laparoscopia (IAL) com SD e adição de PBS (IAL/SD+PBS; $n=38)$.

Para a indução de cio, utilizou-se o seguinte protocolo hormonal: no dia zero (D0) foram aplicadas esponjas intravaginais impregnadas com 60mg de acetato de medroxiprogesterona (MAP) e mantidas por 12 dias (D12). Após a remoção das esponjas (D12), foram administradas injeções intramusculares de 400UI de gonadotrofina coriônica equina (eCG; Novormon ${ }^{\circledR}$ ) e $37,5 \mu \mathrm{g}$ de cloprostenol sódico $\left(\right.$ Sincrocio $\left.^{\circledR}\right)$. A manifestação de cio das ovelhas foi monitorada duas vezes ao dia (oito e 18 horas), a partir da remoção das esponjas até o momento da inseminação artificial em tempo fixo (IATF), com a utilização de dois rufiões vasectomizados que tinham o peito pintado com tinta específica para marcar o posterior das ovelhas em cio, quando montadas. A IATF foi realizada entre 54 a 60 horas após a retirada das esponjas.

O sêmen utilizado em todos os quatro tratamentos foi obtido de um mesmo carneiro da raça Texel com fertilidade comprovada por avaliação andrológica - turbilhonamento $=4$; motilidade progressiva $>70 \%$; vigor $=4 \mathrm{e}$ contagem total de células espermáticas de 2,0 a $2,5 \times 10^{9} / \mathrm{mL}$ em câmara de Neubauer -, a partir da coleta com vagina artificial. Para congelação, foi empregada a metodologia descrita por Anel e
De Paz (2003), com sêmen diluído (1:2; sêmen:diluente - Bovimix ${ }^{\circledR}$, Nutricell), envasado em palhetas de $0,25 \mathrm{~mL}$ com concentração de $240 \times 10^{6}$ e congelado automaticamente na máquina TK3000 SUPER®, utilizando-se o protocolo (P3.S2) descrito pelo fabricante. Posteriormente, foi armazenado em botijão de sêmen contendo nitrogênio líquido até o dia da IATF.

O plasma seminal ovino coletado de três rufiões vasectomizados, por meio de vagina artificial, foi centrifugado a $1500 \mathrm{~g}$ por 10 minutos e colheu-se o sobrenadante que foi estocado a $-20^{\circ} \mathrm{C}$ até a adição deste ao sêmen descongelado no momento da inseminação cervical. Na data da inseminação as palhetas foram descongeladas individualmente pela imersão em água a $37^{\circ} \mathrm{C}$ por 30 segundos, e o conteúdo liberado no interior de um tubo de ensaio mantido em banhomaria a $37^{\circ} \mathrm{C}$, contendo igual volume $(0,25 \mathrm{~mL})$ de PBS ou plasma seminal, conforme o tratamento. Após homogeneização, o volume total de $0,5 \mathrm{~mL}$ - sêmen descongelado + PBS ou plasma seminal - foi novamente acondicionado em duas palhetas de $0,25 \mathrm{~mL}$, sendo as duas utilizadas para inseminar cada uma das ovelhas dos tratamentos T1, T2 e T4.

Para as ovelhas inseminadas via cervical superficial com sêmen fresco diluído, o sêmen foi coletado por vagina artificial, diluído na proporção de 1:2 (sêmen:PBS) e colocado em tubo de ensaio mantido em banho-maria a $37^{\circ} \mathrm{C}$ com igual volume de PBS. No momento da inseminação, eram envasadas duas palhetas de $0,25 \mathrm{~mL}$, e as duas $(0,5 \mathrm{~mL})$ destinadas ao tratamento $\mathrm{T} 3$. Todos os tratamentos receberam volume inseminante total de $0,5 \mathrm{~mL}$. A inseminação artificial cervical foi realizada utilizando-se o aplicador de sêmen de ovinos/caprinos da $\mathrm{IMV}^{\circledR}$. As ovelhas foram contidas e inclinadas com o posterior sobre cavalete de madeira. Após higiene da vulva, com auxílio de espéculo vaginal e lanterna, visualizava-se a cérvix. Posicionou-se o aplicador na entrada da cérvix e administrou-se o conteúdo total de duas palhetas inseminantes.

A inseminação por laparoscopia foi realizada com as ovelhas contidas em maca, em decúbito dorsal, com angulação de $45^{\circ} \mathrm{em}$ relação ao solo. Procedeu-se à anestesia local na região ventral com lidocaína a $2 \%$, em dois pontos localizados 
caudalmente ao umbigo e lateralmente à linha média. O laparoscópio foi introduzido no abdômen empregando-se dois trocateres de $5,5 \mathrm{~mm}$ em pontos anestesiados. Com um dos trocateres foi feita a insuflação da cavidade abdominal com ar comprimido e penetração do laparoscópio, e, com o outro, introduziram-se um manipulador, para auxiliar a localização do útero, e uma pipeta inseminante recoberta com bainha (Aspic $\left({ }^{8}\right)$, com extremidade perfurante, para permitir sua introdução no lúmen uterino e deposição de uma dose de sêmen $(0,25 \mathrm{~mL})$ em cada corno uterino. Decorridos 30 dias após a inseminação, foi realizado o diagnóstico de gestação por ultrassonografia transretal (Aloka Prosound 2®, Formedical, dotado de transdutor linear de $5 \mathrm{MHz}$ ), para determinação da taxa de prenhez. A análise estatística dos dados foi realizada por regressão linear dicotômica $(\mathrm{P}<0,05)$, utilizando-se o pacote estatístico $\mathrm{R}$ (The R Foundation..., 2002).

\section{RESULTADOS E DISCUSSÃO}

Não houve diferença significativa $(P>0,05)$ no percentual de ovelhas identificadas em cio pelos rufiões até o momento da IATF $(59,2 \%, \mathrm{n}=103)$, em relação as que não foram marcadas $(40,8 \%$, $\mathrm{n}=71$ ), sobre a taxa de prenhez do rebanho. A reduzida quantidade de rufiões - dois animais utilizada neste experimento fez com que a relação rufião:ovelha (1:87) estivesse acima da proporção comumente usada em pesquisas, sugerindo que os rufiões não foram capazes de identificar todas as ovelhas que apresentaram cio, pois 15 ovelhas $(8,7 \%)$ estavam prenhes, no exame de ultrassonografia realizado 30 dias após a inseminação. Neste estudo, a taxa de prenhez média dos quatro tratamentos foi de $24,1 \%$.

A adição de plasma seminal ao sêmen descongelado (Tab. 1) não resultou em diferença significativa $(\mathrm{P}>0,05)$ na taxa de prenhez de ovelhas inseminadas via cervical superficial, quando este tratamento foi comparado ao que não recebeu plasma. $\mathrm{O}$ volume inseminante total $(0,5 \mathrm{~mL})$ pode ter influenciado negativamente a taxa de prenhez dos tratamentos com sêmen descongelado pela via cervical superficial, por aumentar o volume líquido em relação à concentração espermática, o que proporcionou maior refluxo seminal no momento da inseminação, e por diminuir a quantidade de espermatozoides depositados no primeiro anel cervical. Doses inseminantes com concentrações mais elevadas de espermatozoides no momento da congelação resolveriam este problema, quando se tem o objetivo de realizar a inseminação cervical superficial com sêmen descongelado adicionado de plasma seminal ou qualquer outra substância para melhorar a viabilidade do sêmen congelado.

Para estudos futuros, sugere-se avaliar a taxa de prenhez de ovelhas inseminadas com sêmen descongelado com adição de plasma seminal em porções mais profundas da cérvix. Isso poderia aumentar a viabilidade da técnica utilizando-a com sêmen descongelado.

Tabela 1. Percentual de prenhez de ovelhas inseminadas em tempo fixo (IATF) pela via cervical, utilizando sêmen descongelado (SD), sêmen descongelado com adição de plasma seminal (SD+PS) e sêmen fresco diluído (SFD)

\begin{tabular}{ccccc}
\hline Tipos de sêmen & N Total & Prenhez (n) & Prenhez (\%) & P-valor \\
\hline SD & 49 & 2 & $4,3 \mathrm{~b}$ & \\
SD+PS & 43 & 3 & $7,0 \mathrm{~b}$ & P $<0,001$ \\
SFD & 44 & 22 & $50,0 \mathrm{a}$ & \\
\hline
\end{tabular}

Médias seguidas de letras diferentes na mesma coluna diferem entre si $(\mathrm{P}<0,05)$.

A taxa de prenhez das ovelhas inseminadas via cervical superficial com sêmen fresco diluído foi maior $(\mathrm{P}<0,05)$ que as outras dos demais tratamentos com a mesma técnica. Este resultado era esperado, uma vez que a motilidade e o vigor do sêmen fresco, mesmo que diluído, são melhores que os do sêmen descongelado.
$\mathrm{Na}$ Tab. 2, verifica-se que a técnica de inseminação cervical superficial resultou em taxa de prenhez $(4,3 \%)$ menor $(\mathrm{P}<0,05)$ que a técnica intrauterina por laparoscopia $(39,4 \%)$ utilizando sêmen descongelado, no volume total inseminante de $0,5 \mathrm{~mL}(0,25 \mathrm{~mL} /$ corno uterino $)$. 
Adição de plasma seminal...

Tabela 2. Percentual de prenhez de ovelhas inseminadas em tempo fixo (IATF), pelas técnicas de laparoscopia e cervical, utilizando sêmen descongelado

\begin{tabular}{ccccc}
\hline Técnica de IATF & N Total & Prenhez $(\mathrm{n})$ & Prenhez $(\%)$ & P-valor \\
\hline Laparoscopia & 38 & 15 & $39,4^{\mathrm{a}}$ & \multirow{2}{*}{$\mathrm{P}<0,001$} \\
Cervical & 49 & 2 & $4,3 \mathrm{~b}$ & \\
\hline
\end{tabular}

Médias seguidas de letras diferentes na mesma coluna diferem entre si $(\mathrm{P}<0,05)$.

Quando o efeito dos tipos de sêmen na inseminação via cervical superficial foi isolado e comparado ao efeito da inseminação via laparoscopia com sêmen descongelado (Tab. 3), a laparoscopia diferiu $(\mathrm{P}<0,05)$ da técnica cervical e apresentou taxas de prenhez mais altas.

Tabela 3. Percentual de prenhez de ovelhas inseminadas em tempo fixo (IATF) pelas técnicas de laparoscopia e cervical

\begin{tabular}{ccccc}
\hline Técnica de IATF & N Total & Prenhez $(\mathrm{n})$ & Prenhez $(\%)$ & P-valor \\
\hline Laparoscopia & 38 & 15 & $39,4^{\mathrm{a}}$ & \multirow{2}{*}{$\mathrm{P}<0,001$} \\
Cervical & 136 & 27 & $20,0 \mathrm{~b}$ & \\
\hline
\end{tabular}

Médias seguidas de letras diferentes na mesma coluna diferem entre si $(\mathrm{P}<0,05)$.

Não houve diferença $(\mathrm{P}>0,05)$ quando foram comparadas as taxas de prenhez dos tratamentos com inseminação artificial cervical e sêmen fresco diluído $(50,0 \%)$ e inseminação via laparoscopia com sêmen descongelado (39,4\%), evidenciando, assim, a escolha da técnica em função do tipo de sêmen utilizado.

A adição de plasma seminal ao sêmen de ovino descongelado quando utilizado pela via cervical superficial não propiciou taxas de prenhez satisfatórias em rebanhos comerciais de ovinos que possam sustentar a indicação dessa metodologia para substituí-la pela técnica via cervical superficial com sêmen fresco diluído e também pela técnica de laparoscopia com sêmen descongelado. Considera-se que estudos são necessários a fim de identificar os fatores limitantes do uso do sêmen descongelado pela via cervical superficial, bem como os aditivos capazes de melhorar sua viabilidade quando utilizados na inseminação convencional.

Resultados de taxas de prenhez ao redor de $50,0 \%$ em rebanhos de ovinos comerciais, quando se utiliza a IATF, são considerados satisfatórios, mesmo dentro da estação reprodutiva, pois, ao contrário da monta natural com carneiro, em que as ovelhas apresentam pelo menos três oportunidades para serem fecundadas, na IATF essas expressam seu potencial reprodutivo de fecundação do óvulo pelos espermatozoides em apenas uma oportunidade.

\section{CONCLUSÕES}

A adição de plasma seminal ao sêmen descongelado e sua deposição pela via cervical superficial, durante a inseminação, não elevou o percentual de prenhez em valores que justifiquem a indicação desta biotecnologia em rebanhos comerciais de ovinos.

\section{AGRADECIMENTOS}

Ao $\mathrm{CNPq}$, pelo financiamento desta pesquisa (Projeto $\mathrm{n}^{\circ}$ 574674/2008-0 e Projeto $\mathrm{n}^{\circ}$ 559182/2010-4), à Cooperativa Coopercapanna e ao médico veterinário Ricardo Lucca, por cederem a propriedade e os animais experimentais.

\section{REFERÊNCIAS}

ANEL, L.; DE PAZ, P. Field and in vitro assay of three methods for freezing ram semen. Theriogenology, v.60, p.1293-1308, 2003.

BICUDO, S.D.; AZEVEDO, H.C.; SILVA MAIA, M.S. et al. Aspectos peculiares da inseminação artificial em ovinos. Acta Sae. Vet., v.33, supl. 1, p.127-130, 2005.

EVANS, G.; MAXWELL, W.M.C. Salamon inseminación artificial de ovejas y cabras. Zaragoza: Acribia, 1990. 191p.

GARNER, D.L.; HAFEZ, E.S.E. Espermatozoides e Plasma Seminal. In: HAFEZ, B.; HAFEZ, E.S.E. Reprodução Animal. 7.ed. Barueri: Manole, 2004. p.97-140. 
GODFREY, R.W.; COLLINS, J.R.; HENSLEY, E.L.; WHEATON, J.E. Estrus synchronization and artificial insemination of hair sheep ewes in the tropics. Theriogenology, v.51, p.985-997, 1999.

KERSHAW, C.M.; KHALID, M.; McGOWAN, M.R. et al. The anatomy of the sheep cervix and its influence on the transcervical passage of an inseminating pipette into the uterine lumen. Theriogenology, v.64, p.1225-1235, 2005.

KIRKWOOD, R.N.; VADNAIS, M.L.; ABAD, M. Practical application of seminal plasma. Theriogenology, v.70, p.1364-1367, 2008.
MAXWELL, W.M.C.; JOHNSON, L.A. Psysiology of spermatozoa at high dilution rates: the influence of seminal plasma. Theriogenology, v.52, p.1353-1362, 1999.

RABASSA, V.R.; TABELEÃO, V.C.; PFEIFER, L.F.M. et al. Efeito das técnicas transcervical e laparoscópica sobre a taxa de prenhez de ovelhas inseminadas em tempo-fixo. Cienc. Anim. Bras., v.8, p.127-133, 2007.

SALAMON, S.; MAXWELL, W.M.C. Storage of ram semen. Anim. Reprod. Sci., v.62. p.77111,2000 . 